\title{
An Exploration of the Relationship between Maternal and Child Factors Contributing to Child Abuse
}

\author{
Yuko Harding ${ }^{1,2^{*}}$, Mitsue Nakamura ${ }^{1}$ \\ ${ }^{1}$ Graduate School of Health Sciences, University of the Ryukyus, Nishihara, Japan \\ ${ }^{2}$ Faculty of Nursing, Chukyo Gakuin University, Mizunami, Japan \\ Email: *yukohardinaha@yahoo.co.jp
}

How to cite this paper: Harding, Y. and Nakamura, M. (2020) An Exploration of the Relationship between Maternal and Child Factors Contributing to Child Abuse. Open Journal of Nursing, 10, 989-1012. https://doi.org/10.4236/ojn.2020.1010070

Received: March 4, 2020

Accepted: October 27, 2020

Published: October 30, 2020

Copyright $\odot 2020$ by author(s) and Scientific Research Publishing Inc. This work is licensed under the Creative Commons Attribution-NonCommercial International License (CC BY-NC 4.0). http://creativecommons.org/licenses/by-nc/4.0/

\begin{abstract}
Background: There are many reports in the mass media and scientific literature about child abuse caused by parents. Medical practitioners also are concerned about child abuse and need to grapple with the prevention and early detection of child abuse when working in medical facilities. Aim: The aim of this descriptive study was to explore the relationship between maternal and child factors contributing to child abuse. Methods: A sample of 50 multiparas (mothers with more than 1 child) in a 48-bed postpartum hospital unit in Okinawa prefecture were asked to fill out an anonymous questionnaire regarding the relationship between mothers and their first child in September, 2007. The questionnaire contained 30 items of physical punishment that are quoted from "The Handbook of Correspondence to Child Abuse" (Ministry of Health, Labor and welfare in Japan), 24 items relating to maternal factors and 22 items to child factors, plus items related to mothers' satisfaction with the health guidance given in the hospital. Data were analyzed using JMP (ver. 14.2; SAS Institute Inc., Cary, NC, U.S.). The significance level was set at 0.05 . Results: Forty-one (82\%) questionnaires were analyzed. Of the 41 valid responses, 19 mothers reported abusing their children. Child factors contributing to the abuse included the first child's regression to infantile behavior, bullying younger brothers or sisters and being rough and violent to their friends. The significant maternal factor leading to abuse was the belief that mothers were irritated by their child. Conclusion: A first child's developmental difficulties had a significant relationship with the harsh punishment by their mothers. The mothers need to understand their child's developmental behavior and provide a favorable environment for nurturing young children.
\end{abstract}

\section{Keywords}

Child Abuse, Factor, Maternal, First Child, Environment 


\section{Introduction}

According to a report by the Ministry of Health, Labor and Welfare, the number of child abuse consultation cases handled at child guidance centers in Japan in fiscal 2017 was 133,778 [1]. The number of cases handled increased by 619 [2]. In Japan, the enforcement of the Child Abuse Prevention Law (Child Abuse Prevention Law) has emphasized the detection and prevention of abuse.

In a 2004 revision, municipalities became the primary point of contact for counseling services, notification of abuse, providing preventive measures against abuse, and providing early home assistance [3]. The abuse was a violation of the human rights of children by law [4].

In a 2007 revision, the function of the Children's Guidance Center was strengthened, and a system to request appearances [5] was established by the prefectural governor (Child Guidance Center). At present, a revision of the Civil Code has established a system to suspend custody from the viewpoint of protecting the rights and interests of children. The state has also made amendments to allow for the appointment of legal entities or multiple minor guardians and has established related provisions [6].

The effects of abuse on children include death, brain damage, antisocial behavior, and mental illness [7]. Without proper treatment, death, or severe physical and mental sequelae are likely to occur [8]. Children form a relationship of trust with their parents and guardians through attachment behavior. But, physical and psychological abuse hinders the relationship of trust, profoundly damages not only physical ability but also the development of the mind and leaves the child injured during childhood [9].

Nurses need to understand the symptoms, disability, and degree of development of their children and their mothers and their families, and acquire nursing skills so that they can be effectively involved as they grow up [10]. Midwives, in particular, play a role in maternal classrooms and midwife outpatients, through opportunities to check on pregnant mothers and their families and health check-ups, to detect child abuse, and contact municipalities when necessary.

The birth of the first child and child care are the first experiences for couples, and they give the family the joy of having one more member. On the other hand, children's illness/disability and injuries increase the stress of childcare on their families, increasing the likelihood that they lead to a crisis, which may result in the breakdown of family functions [11]. Mothers feel a variety of anxiety, stress, and fatigue during childcare after childbirth, and their accumulation sometimes might cause abuse of infants [12]. At the time, the child guidance center, which plays a role in preventing child abuse, receives information on abuse, the attachment relationship between mother and child is often broken [13]. Nurses and midwives encourage mother-child attachment from pregnancy. The beginning of the mother-child relationship is the most important preventive measure against child abuse. From the perinatal period, midwives who can promote the formation of mother-child attachment play a significant role in preventing child abuse. 
There are many reports of abuse of infants caused by childcare difficulties [8], and healthcare professionals must work on prevention and early detection of abuse in medical practice. Cooperation with municipal public health nurses, child guidance centers, police, and hospitals are required [14]. Here we examine mothers with one or more children to determine if they have experienced childcare anxiety, difficulties, or abuse with their first child. The aim of this descriptive study was to explore the relationship between maternal and child factors contributing to child abuse.

\section{Methods}

\subsection{Participants and Procedure}

The participants were 50 multiparous women (about $10 \%$ of the number of births per year) who had gave birth to their first child. An anonymous, self-administered questionnaire survey was conducted at hospital A in Okinawa prefecture for two weeks from September 17, 2007 to September 30, 2007, for women before and after giving birth to their second or more children. We asked mothers what kind of child-rearing anxieties and difficulties, or abuse they have in their relationship with their older child (first child). In conducting this study, we obtained ethical approval from the affiliated organization. The questionnaire was handed directly to the parous women from the three nurses involved in health guidance, explaining the purpose of the survey and ethical considerations. As for ethical considerations, an explanation of privacy protection and the right to refuse to answer and that it will not cause any disadvantage was given, and after filling out the questionnaire, each person was asked to put it in an unmanned collection box. Care was taken not to identify individuals. The main contents of the questionnaire (refer to the materials) are the age of the subject divided by 5 years, the age of the first child, the time and reason for physical and mental difficulties after childbirth, the abuse performed, and abuse Recognition of actions, issues related to childcare anxiety and difficulties experienced in relation to the first child, and issues related to in-hospital health guidance.

Regarding the timing and reasons for physical and mental difficulties after childbirth, we asked multiple answers to select items that corresponded to the timing and reasons. Items selected as abuse were selected from the 30 items of abuse described in the Ministry of Health, Labor and Welfare's "Handbook for Child Abuse" [15], etc. All the actions performed on the first child were selected and circled. Regarding the anxiety and difficulties in child care experienced in relation to the first child, items added from clinical experience to the items reported as factors related to abuse of infants in the preceding literature [15] [16] [17] [18] [19]. The subjects were asked to answer either "Yes" or "No" with 22 questions about the child's situation related to abuse and 24 questions about the mother's situation relating to the abuse.

Regarding the level of satisfaction and the reduction of their stress from the hospital health guidance, the items that we asked about were as follows; a pregnant midwife outpatient, pre-mama class (parents' class), first lactation guid- 
ance, discharge guidance, bathing instruction, breast milk outpatient, one-month postpartum medical examination, and the satisfaction of medical examination for infants after 3 months. They were asked to answer the question in three ways: "Good", "OK" and "Not good" with respect to the former and in two ways: either "Yes" or "No" with respect to the latter. As a mother's request to the hospital for future health guidance, we asked them to answer either "Yes" or "No" for the 6 items (Refer to questionnaire in Appendices).

\subsection{Analysis}

JMP (ver. 14.2; SAS Institute Inc., Cary, NC, U.S.) was used for data analysis.

Descriptive statistics, chi-square test, Fishers' exact test were used for analysis. Regarding participants characteristics, and recognition of abuse/the situation of the first child/status of mothers related to abuse/family environment, mainly $P$ values are from Fishers' exact test analyzed on comparisons between the abuses "Yes" group and the abuse "No" group. The significance level was set at 0.05 .

\subsection{Definition of the Term Abuse Used in This Study}

In this study, we used the term abuse, meaning abusive behavior, because the selected abuse item could not be determined to be abuse. Regarding the literature [20] of the previous study, it was defined as follows. Abusive behavior is a child-rearing activity that requires advice and guidance because there is a danger of developing abuse when escalating, although there are acts such as hitting and scolding, which are consistent acts of discipline.

\section{Result}

\subsection{The Process of the Enrolment and Participant Characteristics}

Responses were obtained from all 50 participants who distributed the survey. Forty-one (82\%) participants were selected, excluding nine mothers with children aged 6 or older whose first child is not an infant. Characteristics of the study participants are listed in Table 1. The age of 41 mothers was 23 (56.1\%) to the early 30s, followed by the late 30 s and the late 20s. In the background of the subjects, no children were born due to unwanted pregnancy or childbirth, and there were no premature babies. All mothers had close friends who talk with participants freely and could take care of their child. Of 41 mothers, the first child age was 2 years for 9 (22.0\%), followed by 8 (19.5\%) mothers each at 1 and 3 years. A comparative study was also conducted in which 19 (46.3\%) mothers who selected one or more abusive items were classified as in the abuse "Yes" group and 22 (53.7\%) were not selected as in the abuse "No" group. In mother's abuse between "Yes" and "No" groups, there was no significant difference in the age distribution of the mothers, and no significant difference in the age distribution of the first child.

\subsection{Contents of Abuse against First Child}

Out of 30 items to be selected as abuse, 19 (46.3\%) mothers selected one or more 
items, and $22(53.7 \%)$ did not select any. Ten mothers selected only one abuse item, six mothers selected two, and one mother each selected three, four, and six.

There were nine selected items of abuse-number of mothers were hitting - $16(84.2 \%)$, followed by loud scolding -9 (47.4\%), pinching -3 (15.8\%), and forcibly dragging $-2(10.5 \%)$. Items that were selected only by one mother (5.3\%) were shaking violently, forcing, kicking, ignoring, and swinging around (Figure 1).

Table 1. Participants characteristics.

\begin{tabular}{|c|c|c|c|c|}
\hline \multirow[b]{2}{*}{ Characteristics } & \multirow{2}{*}{$\begin{array}{l}\text { All mothers } \\
\qquad \mathrm{n}=41\end{array}$} & \multicolumn{2}{|c|}{ Child Abuse } & \multirow{2}{*}{$\begin{array}{c}P \\
\text { values }\end{array}$} \\
\hline & & $\begin{array}{c}\text { Yes } \\
n=19\end{array}$ & $\begin{array}{c}\text { No } \\
n=22\end{array}$ & \\
\hline Mother's age, no. (\%)* & & & & 0.925 \\
\hline$<25$ & $1(2.4)$ & $1(2.4)$ & $0(0)$ & \\
\hline $25-29$ & $5(12.2)$ & $2(4.9)$ & $3(7.3)$ & \\
\hline $30-34$ & $23(56.1)$ & $11(26.9)$ & $12(29.3)$ & \\
\hline $35-39$ & $10(24.4)$ & $4(9.8)$ & $6(14.6)$ & \\
\hline $40-44$ & $2(4.9)$ & $1(2.44)$ & $1(2.4)$ & \\
\hline Age of first child, no. (\%)* & & & & 0.061 \\
\hline 0 -year-old & $7(17.1)$ & $1(5.3)$ & $6(27.3)$ & \\
\hline 1 year old & $8(19.5)$ & $4(21.1)$ & $4(18.2)$ & \\
\hline 2 years old & $9(22.0)$ & $6(31.6)$ & $3(13.6)$ & \\
\hline 3 years old & $8(19.5)$ & $2(10.5)$ & $6(27.3)$ & \\
\hline 4 years old & $4(9.8)$ & $4(21.1)$ & $0(0.0)$ & \\
\hline 5 years old & $5(12.2)$ & $1(10.5)$ & $3(13.6)$ & \\
\hline \multicolumn{5}{|l|}{ Unwanted pregnancy and childbirth } \\
\hline Yes & $0(0)$ & - & - & - \\
\hline No & $41(100)$ & - & - & - \\
\hline \multicolumn{5}{|l|}{ Premature baby } \\
\hline Yes & $0(0)$ & - & - & - \\
\hline No & $41(100)$ & - & - & - \\
\hline \multicolumn{5}{|c|}{ Close friends who talk with participants freely and could take care of their child } \\
\hline Yes & $41(100)$ & - & - & - \\
\hline No & $0(0)$ & - & - & - \\
\hline
\end{tabular}

* $P$ values were from Fishers' exact test analyzed on comparisons between the abuses "Yes" group and the abuse "No" group.

$\mathrm{n}(\%)$ Multiple answers

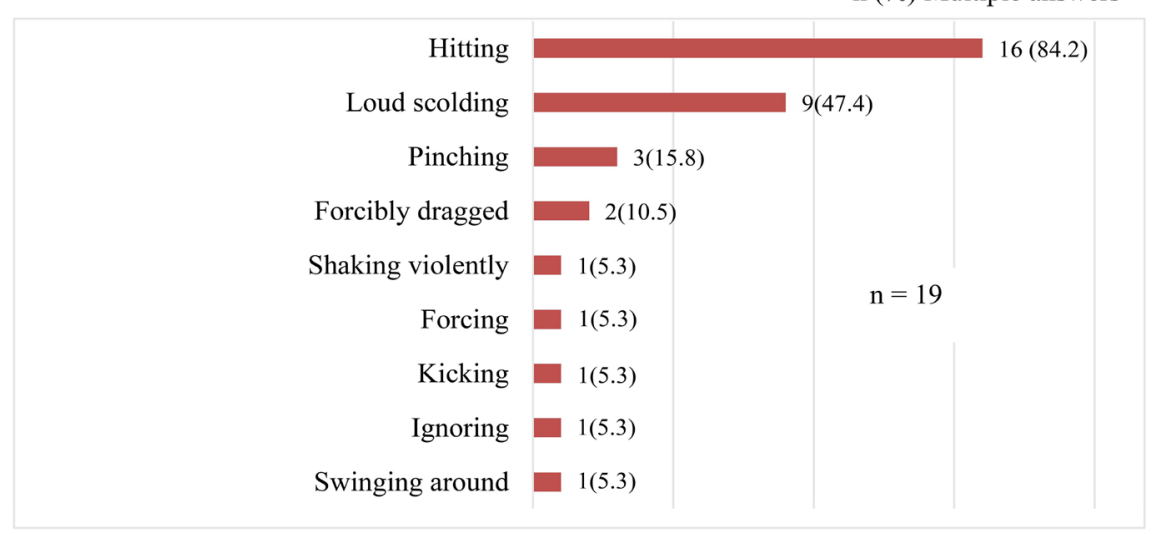

Figure 1. Contents of abuse. 
Five mothers (12.2\%) responded to the abuse of their children's father, and they selected five out of thirty abusive items. The selected contents were hitting -4 , loud scolding -3 , and shake violently -1 , pinching -1 and forcing -1 .

\subsection{When and Why It Was Physically and Mentally Difficult after Childbirth}

As shown in Figure 2, the period of physical and mental difficulties after birth was less than one month after birth, the highest among 22 (53.7\%) out of 41 mothers, and then from one to three months after birth, there was a decreasing trend. None of the mothers chose the physically and mentally difficult period between 6 and 8 months after birth. There were some that were selected as the time when the child moved from nine months to one year old when the child began to move due to crawling and started standing and holding bars. At the age of two, when training for independence and toilet training began, three people answered that it was a difficult time.

Examining the mothers who complained of the persistent difficult period, three people continued to complain from immediately after childbirth to one month, and four people complained from immediately after childbirth to two months, but abuse by numbers was 0 or 1 .

The reason for the physical and mental difficulties after childbirth is as shown in Figure 3. Twenty nine out of 41 people (70.7\%) were lacking sleep, followed by $15(36.6 \%)$ who could not have their own time, and 10 (24.4\%) whose children did not stop crying, 9 (22.0\%) were unable to balance housework and childcare, and 9 (22.0\%) worked on children.

In other description fields, the older child was a handful when giving birth to the younger child $(2.4 \%)$, one mother-in-law came in no matter the time $(2.4 \%)$, and one mother moved to a new house (2.4\%).

\subsection{Perception of the Abuse}

Regarding the 30 abusive items indicated by the Ministry of Health, Labor and Welfare, etc., when asked if they knew that they were abusive, 28 of 41 (68.3\%) indicated that they knew that they were abusive. Looking at this by whether or not the mother was abusive, in the abuse "Yes" group, 6 (35.3\%) answered that they did not know that the abuse was an abuse, which was significantly higher than the 1 (5.6\%) in the abuse "No" group (Figure 4).

\subsection{Relationship between the Situation of the First Child and Abuse by the Mother}

In child situations related to abuse, of the 22 items listed in the questionnaire, the mother of this survey selected 14 items as their first child's situation that they usually feel. The most frequent cases-mother's number were first child's regression to infantile behavior-16 (41.0\%), no close friends to children-9 (25.0\%), height or weight does not follow the development curve of the moth- 
er-child handbook-8 (19.5\%), with hyperactivity (restlessness)-8 (19.5\%), bullying younger brothers or sisters-5 (14.7\%), rough and violent to their friends -4 (9.8\%), and cling on everyone -4 (9.8\%).

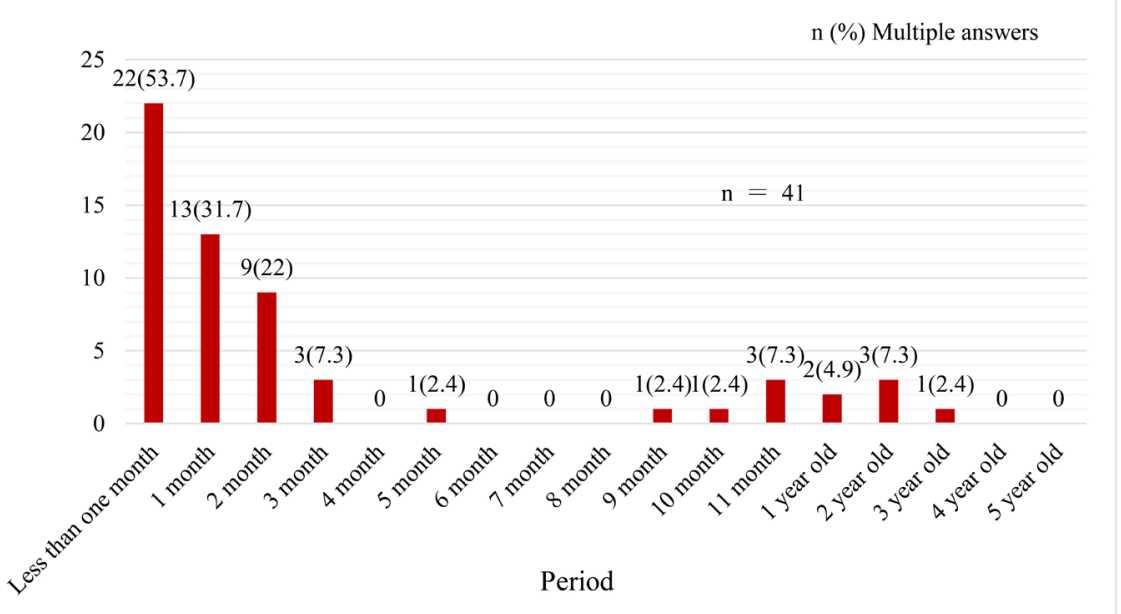

Figure 2. The period of physical and mental hardship after birth.

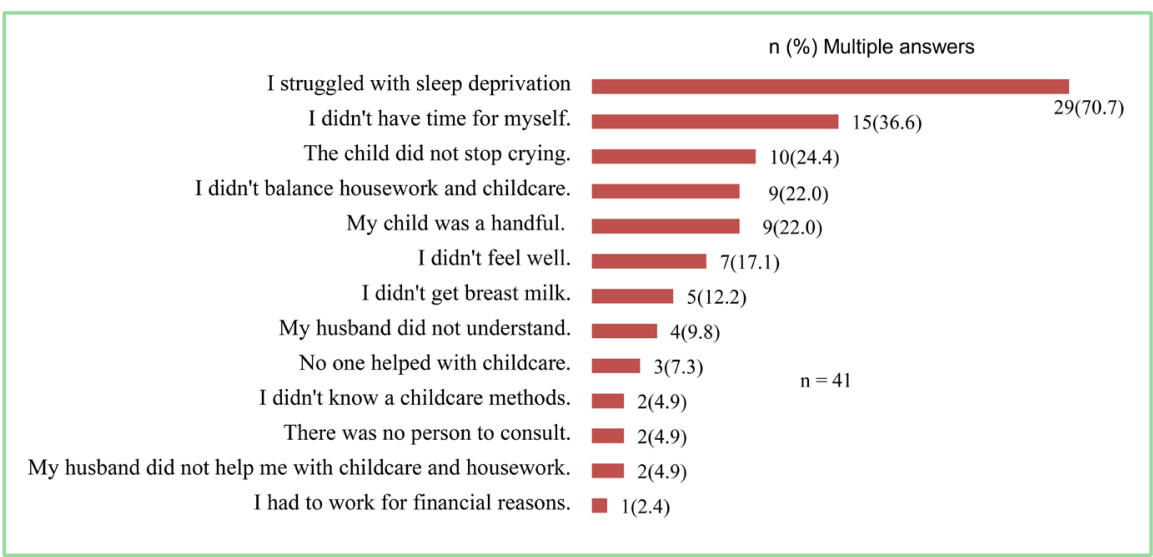

Figure 3. The reason of physical and mental difficulties after childbirth.

$$
\text { Abuse "Yes" group (n = 19) }
$$

$6(35.3)$

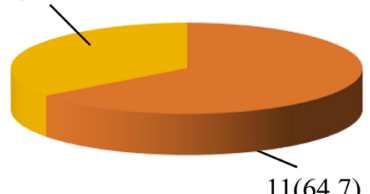

11(64.7)
Abuse "No" group $(\mathrm{n}=22)$

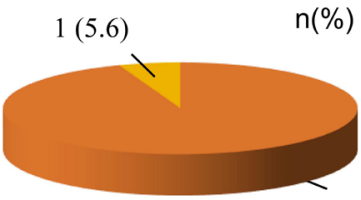

$17(94.4)$

Recognition (-)

Recognition (+)

$$
\chi^{2}=5.230 * P=0.022
$$

Figure 4. Recognition of abuse in the abuse "Yes" or "No" group. * $P$ value was from Fisher's exact test. \%: Missing values were excluded. 
Items that only one mother had selected were delayed in child development/ physical growth, is a twin, often lies down, overeats, gaps in developmental expectations, and is not attached to my husband or the man I'm dating, gets in trouble in kindergarten or preschool. When looking at the situation of the first child related to abuse according to the presence or absence of abuse of the mother, there are significant relations in the two items of first child's regression to infantile behavior and height or weight does not follow the development curve of the mother-child handbook (Figure 5). The rate of first child's regression to infantile behavior was significantly higher among mothers in the abuse "Yes" group. $(P=0.0350)$ In addition, five mothers $(33.3 \%)$ in the abuse "Yes" group answered that their first child bullied their younger brothers or sisters ( $P$ $=0.0108$ ), and there were no mothers in the abuse "No" group. Only four mothers $(21.1 \%)$ in the abuse "Yes" group reported that their children were rough and violent to their friends $(P=0.0383)$. However, a higher proportion of mothers in the abuse "No" abuse group reported that height or weight does not follow the development curve of the mother-child handbook $(P=0.0497)$.

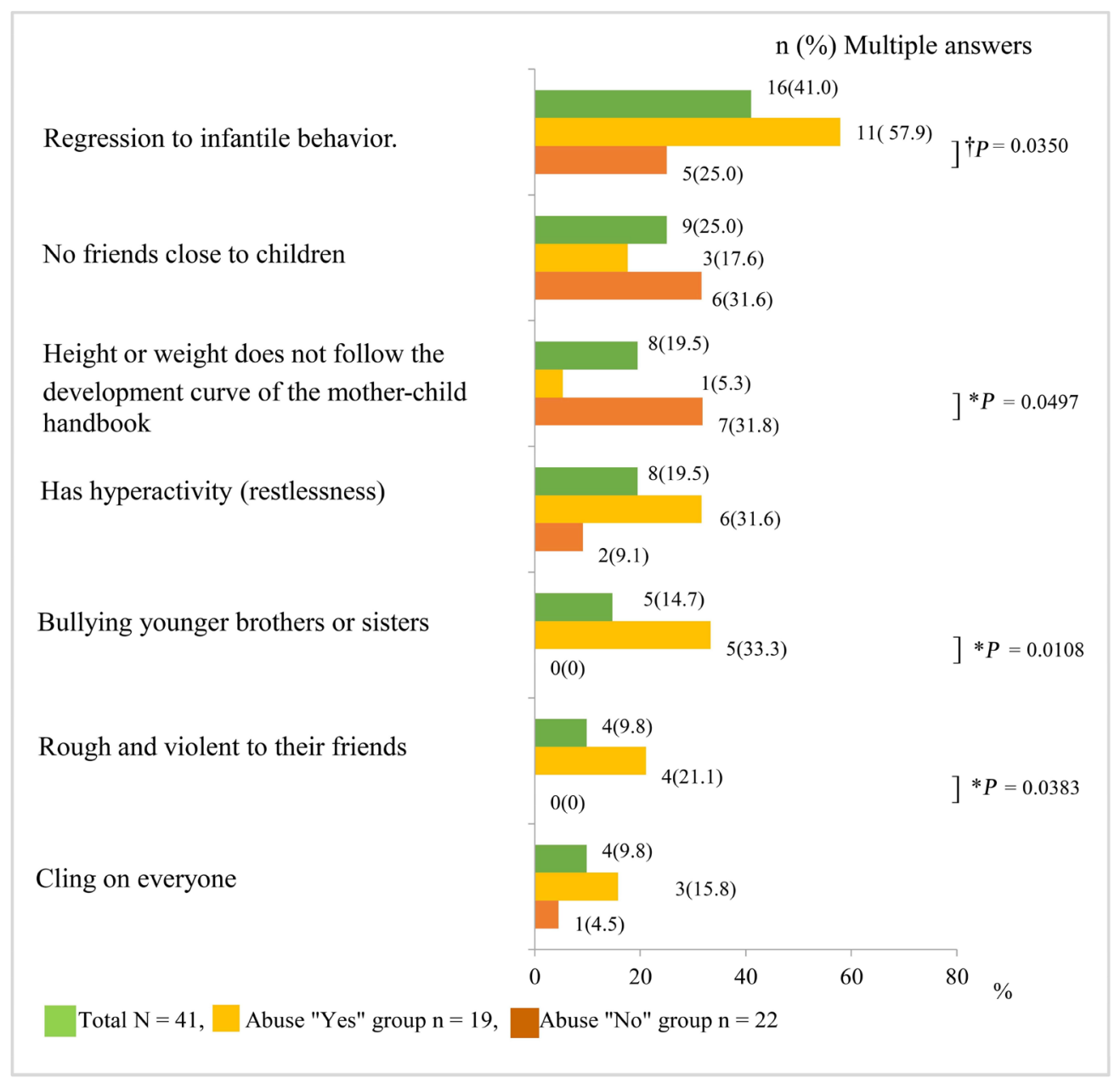

Figure 5. The situation of the first child in the abuse "Yes" or "No" group. * $P$ value was from Fisher's exact test. ${ }^{\dagger} P$ value was from chi-square test. \%: Missing values were excluded. 


\subsection{The Relationship between the Situation of Mothers and the Abuse of the Mother}

Of the 24 items listed in the questionnaire regarding mother status related to abuse, twenty-one items were selected as statuses felt by mothers in this survey, and the main contents-the number of mothers are as shown in Figure 6; thinking other households have been able to raise children well-24 (58.5\%), easily irritated by my child when I don't like my child's behavior-21 (51.2\%), may be frustrated by pregnancy or childbirth-19 (46.3\%) etc. The items that only one mother had selected were that sometimes she doesn't feel any affection for her child, and sometimes she wishes that her child would disappear, has trouble with her neighborhood, and she thinks she wasn't loved by her parents. When looking at the situation of mothers by whether or not they were abusive, there was a significant difference only in "I am easily irritated by my child when I don't like my child's behavior" ( $P=0.0016)$. Mothers who reported abuse were significantly more likely to be irritated by their children when they did not like their behavior (Figure 6).

\subsection{Relationship between Family Environment and Abuse}

Three (15.8\%) mothers in the abuse "Yes" group reported that their children sometimes eat alone while watching TV, however, while those in the abuse "No" group, nothing was answered by mothers $(P=0.106)$. In addition, three mothers (15.8\%) had a history of alcohol abuse among mothers in the abuse "Yes" group and none in the abuse "No" group $(P=0.909)$.

\subsection{Mother's Request for Health Guidance at Hospital}

Regarding the health guidance at hospital A, about $70 \%$ of the respondents were satisfied with the guidance from the hospital and $80 \%$ answered that they had a stress-reducing effect. The rate of response to health guidance questions was low, with only two-thirds of mothers responding, so a detailed analysis was not performed. Although there was no significant relationship between mothers' requests to the hospital, the only request for mothers in the abuse "Yes" group was to conduct home-visit nursing for childcare. However, no one requested consultation on abuse.

\subsection{Four Cases of Abuse and the Characteristics of Their Mother and Child (Table 2)}

1) Case $1<$ Mother shakes baby hard $>$

Case 1 is a mother with a first child under one year of age who chooses to shake her child violently. The reasons for the physical and mental difficulties were that the child was a handful and that the child did not stop crying. The mother's situation related to the abuse was troubled by her lack of childcare, argument with her husband, and her relationship with her parents. The mother answered there was no abuse from her husband against her children.

2) Case $2<$ Case where the child has delayed development or growth $>$ 
Case 2 is a mother who responded to her 4-year-old first child with hitting, forcing, and swinging. The mother experienced sleep deprivation and the inability to balance both housework and childcare. She answered that her children's father had hit or forced his child. The mother stated that her first child was violent, without following the development curve, regressed, and hyperactive. In the mother's situation, the mother believed that she was unqualified as a parent, and had concerns over her relationship with her parents and financial anxiety.

3) Case 3 <Case where mother has a history of regular alcohol use $>$

In Case 3, the abuse was only hitting and claimed not to know that it was an abuse. She complained that her first child, one year old, had hyperactivity and had no close friends, and said that on the mother's side, she has a history of regular alcohol use and did not want to do housework.

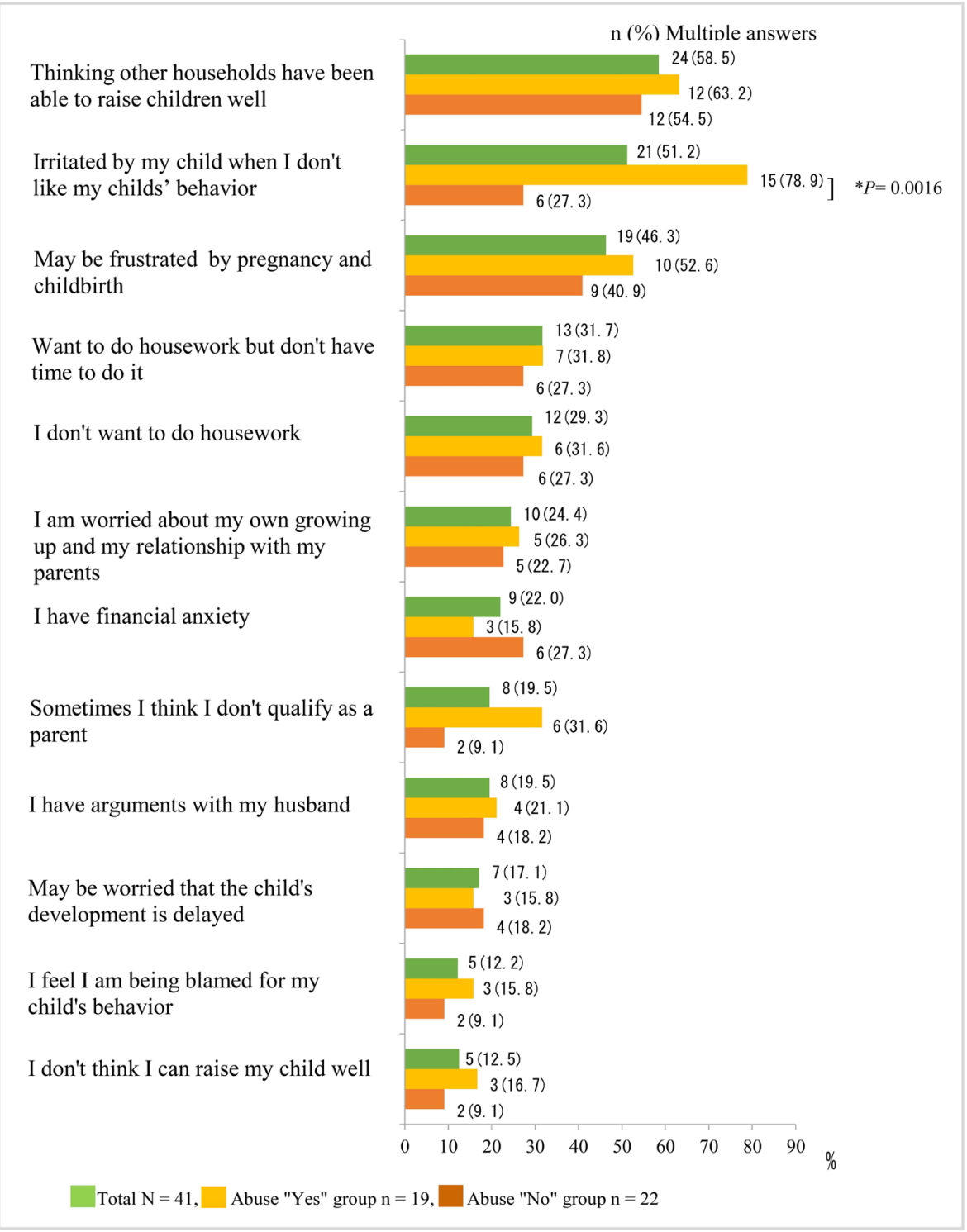

Figure 6. Status of mothers related to abuse in the abuse "Yes" or "No" group. * $P$ value was from Fisher's exact test. \%: Missing values were excluded. 
Table 2. Four cases of abuse and the characteristics of their mother and Child.

\begin{tabular}{|c|c|c|c|c|}
\hline Variable & $\begin{array}{l}\text { Case } 1 \\
\text { A mother shakes the baby } \\
\text { violently }\end{array}$ & $\begin{array}{l}\text { Case } 2 \\
\text { A Mother's child has a delay } \\
\text { in development or growth }\end{array}$ & $\begin{array}{l}\text { Case } 3 \\
\text { A mother with a history } \\
\text { of regular alcohol use }\end{array}$ & $\begin{array}{l}\text { Case } 4 \\
\text { A mother who was abused } \\
\text { by her parents }\end{array}$ \\
\hline 1) Mothers' age & Late $20 \mathrm{~s}$ & Late $20 \mathrm{~s}$ & Early 30 's & Early 30 's \\
\hline 2) Age of first child & Under 1 year old & 4 years old & 1 year old & 2 years old \\
\hline $\begin{array}{l}\text { 3) Hard time after } \\
\text { childbirth }\end{array}$ & One month & Less than 1 month & Two months & $\begin{array}{l}\text { Less than } 1 \text { month/ One } \\
\text { month }\end{array}$ \\
\hline $\begin{array}{l}\text { 4) Reasons why it was } \\
\text { hard after childbirth }\end{array}$ & $\begin{array}{l}\text { Handful child } \\
\text { Child crying }\end{array}$ & $\begin{array}{l}\text { Sleep deprivation } \\
\text { No balance housework and } \\
\text { childcare. }\end{array}$ & $\begin{array}{l}\text { Sleep deprivation } \\
\text { No time for myself/Child } \\
\text { crying }\end{array}$ & $\begin{array}{l}\text { Sleep deprivation } \\
\text { No breast milk/Handful child }\end{array}$ \\
\hline $\begin{array}{l}\text { 5) Abuse } \\
\text { Mother }\end{array}$ & Shaking violently & $\begin{array}{l}\text { Hitting, Kicking, Pinching, } \\
\text { Loud Scolding, Forcing, } \\
\text { Swinging around }\end{array}$ & Hitting & Hitting \\
\hline Partner & No abuse & Hitting, Loud scolding, Forcing & No abuse & No abuse \\
\hline 6) Recognition of abuse & (Unanswered) & Recognition $(+)$ & Recognition (-) & Recognition $(+)$ \\
\hline $\begin{array}{l}\text { 7) First child situation } \\
\text { associated with abuse }\end{array}$ & $\begin{array}{l}\text { (No adaptation items } \\
\text { because of small Child) }\end{array}$ & $\begin{array}{l}\text { Not following the development } \\
\text { curve } \\
\text { Regression/ hyperactivity } \\
\text { Rough and violent to his/ her } \\
\text { friends } \\
\text { Bullying younger brothers or } \\
\text { sisters }\end{array}$ & $\begin{array}{l}\text { Hyperactivity/no close } \\
\text { friends }\end{array}$ & $\begin{array}{l}\text { Regression } \\
\text { Rough and violent to his/her } \\
\text { friends } \\
\text { Bullying younger brothers or } \\
\text { sisters }\end{array}$ \\
\hline $\begin{array}{l}\text { 8) Mother situation } \\
\text { associated with abuse }\end{array}$ & $\begin{array}{l}\text { Irritated by child's behavior } \\
\text { Blamed for child's behavior } \\
\text { Not raising child well } \\
\text { Arguments with husband } \\
\text { No conversation with } \\
\text { husband } \\
\text { Worried about growing } \\
\text { up and relationship with } \\
\text { parents }\end{array}$ & $\begin{array}{l}\text { Not raising children well } \\
\text { Unqualified as a parent } \\
\text { Arguments with husband } \\
\text { Worried about growing up } \\
\text { and relationship with parents } \\
\text { Financial anxiety/Want to do } \\
\text { housework but don't have time } \\
\text { to do it }\end{array}$ & $\begin{array}{l}\text { Irritated by child's beha- } \\
\text { vior } \\
\text { Currently or ever consume } \\
\text { alcohol } \\
\text { Frustrated by pregnancy } \\
\text { and childbirth } \\
\text { Want to do housework but } \\
\text { don't have time to do it }\end{array}$ & $\begin{array}{l}\text { Irritated by child's behavior } \\
\text { Not raising children well } \\
\text { My child discriminated } \\
\text { against by grandparents } \\
\text { Remember that I was also } \\
\text { abused } \\
\text { Frustrated by pregnancy/ } \\
\text { childbirth } \\
\text { Want to do housework but } \\
\text { don't have time to do it }\end{array}$ \\
\hline
\end{tabular}

4) Case $4<$ Case of mother abused by parent>

The only abuse in Case 4 was hitting, she knew it was abusive. She stated that her two-year-old first child was regressed and violent, and that on the mother's side the mother had also been abused by her parents.

\section{Discussion}

\subsection{Current Status of Abuse by This Survey}

According to the Japan Children's Health Association “Infant Health Survey, 2000 " [21], it has been reported that $20 \%$ of mothers answered that they think they may be abusing their children, in a previous study, $46.3 \%$ of all mothers had abused their first child. In 2008, the Ministry of Health, Labor and Welfare broken down child abuse consultation types [22], with physical abuse accounting for $38.3 \%$, neglect $37.3 \%$, psychological abuse $21.3 \%$, and sexual abuse $3.1 \%$. In addition, the composition of abusers in the above categories was $60.5 \%$ by mothers, $24.9 \%$ by mothers, $6.6 \%$ by non-mothers, and $1.3 \%$ by mothers-in-law. 
Mothers were more likely than fathers to abuse the children. According to this survey, most of the actions selected by the mother were only nine items, such as hitting, loud scolding, and so on. These included cruel abuse such as soaking in water, burning with fire and sexual assault on children. The mothers' abuses in this study were unlikely to be fatal, and could be described as a form of disciplinary abuse.

\subsection{Status of First Child Related to Abuse and Its Response}

The results of this survey suggest that the three situations of first child's regression to infantile behavior, bullying younger brothers or sisters, and being rough and violent to friends are related to the abuse that mothers give to their children. For this reason, midwives do not only focus on the status and problems of their current pregnant mother and fetus when giving health guidance to parous women, and it is important to incorporate the developmental status and personality of other children, including the first child, into the topic and gain clues to prevent abuse.

In particular, during pregnancy guidance, mothers who have older children that regress, bullying younger brothers or sisters, or who say they are violent to their friends should be asked about the age and distress of the older children. It will be necessary to listen carefully to the details in order to get information and to think about the response together. Regression, bullying younger brothers or sisters, and violent behaviors seen in late childhood often resulting from frustration that the first child's mother was taken by the younger baby, who is a sibling.

In response, when the younger child is sleeping, the parents need to intensively care for the older child, or give them privileges or special time such as "You are an older brother (or older sister), so I will take you shopping." It is important to consider ways that the first child's problematic behavior does not appear, such as that the father spends time with the older child on behalf of the mother. It appears that hospital pregnancy health guidance programs tend to focus primarily on the mother and her fetus. In the future, the father (or key person) will be required to cooperate more and more in the prenatal parent class and midwife outpatient, or postpartum discharge guidance and breastfeeding outpatients. It is necessary to consider guidance including how to interact with the above children while taking into account the family background. To reduce abuse arising from the situation of the first child, midwives should help mothers fully understand the child's growth and psychological development, not only during the newborn and early infancy, but also up to school. It is important to learn how to cope, to create an environment where mothers themselves can cope with the problems of the child's development process and can afford childrearing. In childhood, it is necessary to approach not only intellectual linguistic stimuli but also a method of disciplining basic lifestyles that must be acquired according to the stage of development [23]. In childcare, it is necessary that the child's environment be adjusted so that the child can grow and develop physically, psychologically and socially in a well-balanced manner. 


\subsection{Mother's Situation Related to Abuse and Response}

In the mother's situation related to abuse, the item of getting irritated by their children when they did not like the first child's behavior was significantly higher among mothers who answered that they had committed abuse. Therefore, it is necessary to ask mothers about their feelings toward their first child and whether they have difficulties in raising children.

According to a survey by the Osaka Health Center, the number of mothers who answered that "mothers often get irritated by their child when staying with children" increased from $10.8 \%$ in 1981 to $30.1 \%$ in 2000 . The following have been reported on the factors. Mothers who have lived in the era of low birth rate and have insufficient experience of contacting and raising children, other than their own, before pregnancy.

There have been reports of psychological stress associated with retirement due to childbirth and lack of childcare support due to the nuclear family, weakening of human relations in the community, and lack of cooperation with childcare and housework by less than ideal husbands [24].

The situation at the time of abuse by the abusers was a feeling of irritation, accounting for $41.3 \%$ [25]. It has also been suggested that there is a significant relationship between mental disorders such as mother's depression and aggression and abuse against children [26]. This suggests that during pregnancy and puerperal instruction, mothers with a strong sense of depression and frustration should be able to express how they are irritated by children. We need to be able to calmly reflect on their daily actions and discuss ways to reduce frustration and anger.

\subsection{Environmental Factors Associated with Abuse and Response}

Four mothers, whose children may eat alone while watching TV, and three mothers with a history of alcohol abuse, reported being abusive. It is thought that various household circumstances have caused child solitude. It has been reported that children under 2 years of age are more likely to be aggressive if placed in a parental neglect environment [27]. While parents and children eat together, and families have fun with their children, an environment that allows both parents and children to grow together is required. Also, alcohol use by three out of 41 people is not a desirable environment for children. The need for assessment and treatment of post-traumatic stress disorder in children exposed to physical violence and neglect due to mothers' alcohol abuse is stated [28]. It is necessary to ask a clinical expert for support so that the mother does not escape to alcohol use.

\subsection{Support for Mother's Physical and Mental Difficulties up to 3 Months after Childbirth}

Many mothers complain of postpartum fatigue in the 2nd week or 1 month postpartum due to infant health checkups and breast milk outpatient service, etc. 
According to the results of 41 mothers in this survey, the period of physical and mental difficulties after childbirth was the highest at less than one month, and gradually decreased from one month to three months after childbirth. It has been reported that $20 \%-30 \%$ of mothers felt uncertainty, mental illness, and difficulties in handling children during the one-month postpartum checkup [29]. It is necessary to listen to complaints about mothers' sleep deprivation, lack of their own time, and children's inability to stop crying at the time of child health check-ups and outpatients' breastfeeding after discharge. We believe that it is possible to reduce mother's postpartum pain by taking care of the mother's poor physical condition and childcare anxiety, and providing guidance including the whole family and helping to connect to the community.

\subsection{Mother's Request to Hospital and Necessity of Home-Visit Nursing}

There was no significant relationship between mothers' requests to the hospital, the only request for mothers in the abuse "Yes" group was to conduct home-visit nursing for childcare. In the case of child abuse deaths, there is a feature that the abuse is escalated without the necessary access to a counseling facility [30]. In order to prevent abuse, it is important to express the problems of mothers by visiting nursing care [31] and access supported by e-mail. In addition, abuse cases are included in a high proportion of those who have high levels of health center services but do not take advantage of their services in the region [32].

Therefore, it is very important in the community to determine whether the relationship between mother and child during a newborn visit is good. For this reason, in the hospital, it is necessary to identify and support mothers who have strong anxiety about childcare who need home-visit nursing during hospitalization, and to ensure that they are connected to local medical institutions after discharge. Opportunities for information exchange between comrades who support families on their websites [33] are an increasingly important part of providing early and long-term assistance to problem mothers and their families to prevent abuse and neglect.

\subsection{Responding to Four Cases of Abuse and Providing Individual Guidance}

In Case $1<$ the case that Mother shakes the baby violently>, the reasons for the physical and mental difficulties of the mother were that the child is a handful and that the child did not stop crying. There have been reports [34] that mothers who engaged in physical abuse took infant crying more negatively. For mothers who do not know how to respond to children's crying, it is necessary to take an approach to affirm a difficult situation of childcare by showing concrete methods of responding instead of leaving the child alone. For example, during health guidance, if the baby does not stop crying, it is necessary to gently hold the baby and convey the negative effects of shaking the baby with anger. It is said that hugs increase the emotional response of both the child and the mother, and 
foster relationships with people and the ego [35]. It is necessary to discuss with the mother how to cope when the baby does not stop crying [35] [36] and provide practical instruction on how to relate to the baby.

For situations such as lack of confidence in childcare and disagreement with the husband (passing), in order to reduce the stress of the wife, it is necessary to give advice not only to mothers but also to fathers on how to use social resources [37], such as childcare circles and "mom friends". It is important to work with the couple and to work together so that they can cooperate and participate in childcare to enhance maternal and paternal care.

The majority of the deaths caused by abuse were under the age of one, accounting for about 46.2\% (30 babies of all 65 cases in Apr. 2017-Mar. 2018) in Japan, and in particular, about $46.7 \%$ of all 0 -year-old were younger than 1 month [38]. Early support may be needed for mothers and families with infants as part of abuse prevention.

In Case $2<$ the case that the child has a delay in development or growth>, in addition to child problems such as regression, hyperactivity and violence, mothers, including those without parental qualifications, also had problems with themselves and reported that their fathers were abusive. Mothers and fathers who have such problems should check whether their mother's self-responsibility or self-esteem has declined during maternal and child health guidance, and in the background, if they have concerns about their own upbringing and their relationship with parents. It is necessary to confirm consciousness and anxiety about childcare, observe parent-child/marital relations, and the state of mind of mother and child, and provide counseling from a specialist as well as care. In addition, in promoting the formation of parent-child attachment, the child and childcare environment should be designed so that mothers and fathers can afford and enjoy child-rearing [39] for the mental health of children in infancy. It is important to encourage children and their parents to grow together while watching their development.

In Case $3<$ the case that the mother had a history of regular alcohol use>, she had a one-year-old child and said she was irritated by her children when she didn't like the child's behavior. The mothers' alcohol abuse was a factor in the child abuse [28], and all three mothers with alcohol abuse found in this survey also reported being abusive. For mothers who have used alcohol regularly, in cooperation with in-hospital and local staff, we aim to express the mother's psychological and social concerns and provide guidance so that the mother can take a positive perspective on the growth and development of the child.

To avoid alcohol use due to loneliness, support for establishing a mother-child relationship, raising the relationship between parents and children, and strengthening childcare support such as psychological consultation on childcare anxiety and parent-child group work will be issued for maternal and child health in the future. Care for mothers at risk of abuse needs to be reliably transferred from hospitals to local health centers and child counseling centers.

In Case $4<$ the case of a mother who was abused by her parents $>$, her only 
abuse was hitting. The mother had problems with her first child, including first child's regression to infantile behavior and violence, and she had been abused. This time, because of the anonymous questionnaire, mothers answered whether or not they had been abused in the past, but few mothers would say that they were abused during face-to-face guidance. It is difficult to hear and get the answer of abuse from the mother in-person. For this reason, it is very difficult to identify a mother who has been abused in the past during health guidance.

It has been reported that mothers who have been abused are more likely to have trouble with their mothers during pregnancy or before and after childbirth, and that postnatal infants are more likely to have medical problems [40]. It has also been reported that approximately $30 \%$ of mothers who have been abused have abused their children [41]. When consulting such mothers, look at the protective factors (compensation factors) that work to prevent abuse and encouraging them with the idea that your childcare does not directly reflect abuse experience [42] is required. It is desirable to work with non-abused parents, close friends, therapists, spouses and partners, etc. who have good human relationships and self-efficacy, including academic ability.

Mothers who abuse their children are partly caused by attachment-related disorders [43], and it is necessary to provide childcare support to mothers whose mothers and infants have an unstable internal working model [44]. Midwives are expected to support the formation of attachment to the fetus during pregnancy [13]. For childcare difficulties due to regression of the first child and violence, it will be necessary to provide detailed guidance on how to handle and express affection for children during pregnancy.

\subsection{Limitations of This Study}

This study is a limited-time survey of one hospital, and the number of subjects is also limited. Therefore, it is necessary to increase the number of cases in the survey and further verify the reliability of the results of this survey.

\section{Conclusion}

A questionnaire was distributed to 50 people, and $41(82 \%)$ valid responses were analyzed. Nineteen mothers who selected one or more out of 30 abuse items were classified as abusive. The abuse "No" group had 22 people. Especially, the rate of first child's regression to infantile behavior was significantly higher among mothers in the abuse "Yes" group. The item of height or weight values not along the growth curve of the mother and child handbook was significantly higher among mothers in the abuse "No" group. Mothers who reported that their first child bullied the younger brothers or sisters or that the child was rough and violent to their friends were seen in the abuse "Yes" group only but not in the "No" group. Mothers who reported abuse were significantly more likely to be irritated when they did not like the child's behavior. 


\section{Funding}

This research did not receive any specific grant from funding agencies in the public, commercial, or not-for-profit sectors.

\section{Authors' Contributors}

Yuko HARDING: participated in the conception and design, acquisition of data, analysis and interpretation of data, drafting the article, revising it for intellectual content, and final approval of the finished article.

Mitsue NAKAMURA: analysis and interpretation of data, revising it for intellectual content, and final approval of the finished article.

\section{Conflicts of Interest}

The authors declare no conflicts of interest regarding the publication of this paper.

\section{References}

[1] Ministry of Health, Labor and Welfare (2019) The Number of Child Abuse Consultations Handled at the Child Guidance Center etc in 2017. https://www.mhlw.go.jp/stf/houdou/0000190801_00001.html

[2] (2019) Number of Child Abuse Consultations Handled at Child Guidance Centers. https://www.pref.okinawa.jp/site/kodomo/shonenkodomo/jidougyakutaisoudanken nsuu.html

[3] Takahashi, S. (2007) Japanese Child Home Welfare: Sixty Years of History of the Child Welfare Act. Akashi Shoten, Tokyo, 219. https://ci.nii.ac.jp/ncid/BA84370196?l=en

[4] Miyamoto, S. (2008) Outline of Child Abuse and Neglect. Japanese Journal on Developmental Disabilities, 30, 64-76. https://ci.nii.ac.jp/naid/10021279573

[5] Ministry of Health, Labor and Welfare: Law on Prevention of Child Abuse and Law Revision of Part of Child Welfare, Article 4.2.

https://www.mhlw.go.jp/bunya/kodomo/dv-boushikaisei19-youkou.html

[6] Ministry of Health, Labor and Welfare, Latest Law Revision Related to Child Abuse. https://www.mhlw.go.jp/seisaku/2011/07/02.html

[7] Kaplan, K.M., Gruson, K.I. and Paksima, N. (2008) Bilateral Humerus and Corner Fractures in an 18-Month-Old Infant-A Case Report and Review of Child Abuse from the Resident Perspective. Bulletin of the NYU Hospital for Joint Diseases, 66, 124-128. https://www.ncbi.nlm.nih.gov/pubmed/18537782

[8] Miyamoto, S. (2008) Understanding and Responding to Child Abuse. The Japanese Society of Pediatric Surgeons, 44, 323. https://www.jstage.jst.go.jp/article/jjsps/44/3/44_KJ00004986472/_article/-char/ja

[9] Hayashi, T. (2008) Child Abuse as a Risk/Hate Factor for Developmental Disorders. Japanese Journal of Developmental Disabilities, 30, 82-91. https://jglobal.jst.go.jp/en/detail?JGLOBAL_ID=200902201028497650

[10] Arai, Y., Yasutake, S., Kasagi, K. and Okamitsu, K. (2008) An Investigation on the Supports and Linking Systems for Nurses in Medical Institutions and Community Health Institutions Preventing Child Abuse. Humanity and Science, 8, 101-115. https://ci.nii.ac.jp/naid/110007025319 
[11] Mori, M. (1994) Trends in Family Nursing Research in Maternal and Child Nursing in Japan. The Japanese Journal of Nursing Research, 27, 43-48. https://webview.isho.jp/journal/detail/abs/10.11477/mf.1681900186

[12] Hanada, H., Nagae, M., Oishi, K. and Honda, S. (2007) The Reliability and Validity of Child Abuse Risk Potential Screening Scale. Health Science Research, 19, 51-58. https://ci.nii.ac.jp/naid/110006448346

[13] Teraoka, S., Tajima, C., Yoshida, K., Ikuta, M., Miyazato, K. and Hashiguchi, M. (2008) Concerning Child Abuse (the Second Report) - The Role of Midwives in the Prevention of Child Abuse. Bulletin of Kumamoto University, School of Health Sciences, 4, 59-69. https://ci.nii.ac.jp/naid/110006593863/

[14] Nakama, T., Kinjyo, A., Yanagi, Y. and Miyagi, M. (2008) The Role of Pediatric Surgeons in the Center Hospital for Child Abuse (Requested Theme Session 3 Child Abuse, Better Life for Sick Children, Better Future for Pediatric Surgery, the 45th Annual Meeting of Japanese Society of Pediatric Surgeons). Journal of the Japanese Society of Pediatrics Surgeons, 44, 347.

https://www.jstage.jst.go.jp/article/jjsps/44/3/44_KJ00004986517/_article/-char/en

[15] Ministry of Health, Labor and Welfare (2007) Amendments to Guidelines for Child Abuse. http://www.mhlw.go.jp/bunya/kodomo/dv12/index.html

[16] Project Team on Developing Child Abuse Prevention Activities (2006) Development of Child Abuse Prevention Activities. Guidance on Using a Child Abuse Prevention Screening System (Issued in 2004). Minamitama Health Center, Tokyo, 1-24. https://ci.nii.ac.jp/ncid/BA67800277

[17] Tokyo Metropolitan Government Bureau of Social Welfare and Public Health, Low Birth Society Department (2005) Child Abuse II-Let's Shine the Future of Children, Let's Bring Up Local Network. Tokyo Metropolitan Government Bureau of Social Welfare and Public Health, Low Birth Society Department, Tokyo, 66-67. https://iss.ndl.go.jp/books/R100000002-I000008086614-00?locale=en\&ar=4e1f

[18] Maternal and Child Group, Health Promotion Section, Health Care Room, Health and Medical Department, Osaka Prefectural Government (2006) Viewpoint for Prevention of Child Abuse (Abuse Prevention Manual) What Medical Institutions Can Do to Create a Child-Friendly Society. Maternal and Child Group, Health Promotion Section, Health Care Room, Health and Medical Department, Osaka Prefectural Government, Osaka, 11-14.

[19] Sato, T. (2002) Community Health Manual for Child Abuse Prevention: From the Perspective of Child Abuse Prevention, Child Abuse Prevention Community Health Study Group. Syakaihokenkenkyusyo, Tokyo. https://ci.nii.ac.jp/ncid/BA62120901?l=en

[20] Nishimura, M., Tsuda, A., Hayashi, C., Kimura, R., Seki, H., Sakai, A., Shimada, K., Tabuchi, N., Sumitani, M. and Kameda, Y. (1999) Mother's Anxiety of Child Rearing and Child Abuse. University Extension Journal of Kanazawa University, 19, 121-126. https://ci.nii.ac.jp/naid/110004826933

[21] The Japanese Society of Child Health (2001) Infant Health Survey Report, 2000. http://www.jschild.or.jp/book/report_2000.html\#five

[22] Ministry of Health, Labor and Welfare (2008) Overview of the Results of the Social Welfare Administrative Work Report (Welfare Administrative Report Example). http://www.mhlw.go.jp/toukei/saikin/hw/gyousei/08/kekka8.html

[23] Ueda, R., Yasuda, Y. and Maeda, K. (2008) Child-Rearing Behavior for Pre-School Children at M City in One of the Most Southern Islands of Japan in Relation to the Prevention of Child Maltreatment: Similarities and Differences between 1984-2006. 
Japanese Journal of Health and Human Ecology, 74, 99-113.

https://doi.org/10.3861/jshhe.74.99

https://ci.nii.ac.jp/naid/10027578891

[24] Welfare Labor White Paper 2003. pp. 22-3. http://www.mhlw.go.jp/wp/hakusyo/kousei/03/dl/data.pdf

[25] Hagiwara, T. and Iwai, Y. (1998) Child Abuse and Countermeasures: Based on a Surve. Taga Shuppan, Tokyo, 34. http://www.law.keio.ac.jp/ hkatoh/gyakutai/2_1_B.htm

[26] Conron, K.J., Beardslee, W., Koenen, K.C., Buka, S.L. and Gortmaker, S.L. (2009) A Longitudinal Study of Maternal Depression and Child Maltreatment in a National Sample of Families Investigated by Child Protective Services, Archives of Pediatrics and Adolescent Medicine, 163, 922-930.

https://www.ncbi.nlm.nih.gov/pubmed/19805711

https://doi.org/10.1001/archpediatrics.2009.176

[27] Kotch, J.B., Lewis, T., Hussey, J.M., English, D., Thompson, R., Litrownik, A.J., Runyan, D.K., Bangdiwala, S.I., Margolis, B. and Dubowitz, H. (2008) Importance of Early Neglect for Childhood Aggression. Pediatrics, 121, 725-731.

https://www.researchgate.net/publication/5470236

https://doi.org/10.1542/peds.2006-3622

[28] Conners-Burrow, N.A., Johnson, B. and Whiteside-Mansell, L. (2009) Maternal Substance Abuse and Children's Exposure to Violence. Journal of Pediatric Nursing, 24, 360-368. https://www.ncbi.nlm.nih.gov/pubmed/19782894 https://doi.org/10.1016/j.pedn.2008.03.006

[29] Kobayashi, Y., Endo, T., Hiejima, Y., Amemiya, S., Osada, Y., Tanabe, K. and Nakamura, Y. (2006) Mothers' Feelings of Difficulty with Child Rearing of One-Month-Old Children. Yamanashi Nursing Journal, 5, 9-16.

https://ci.nii.ac.jp/naid/110006386816

[30] Suzuki, A., Fujisawa, N., Mizushina, K., Baba, N., Horii, A. and Kasai, T. (2008) A Study of the Process of Fatal Child Abuse and Neglect in Judicial Decisions: Evidence Based Practice (EBP) to Support Powerless Families. Japanese Journal of Child Abuse and Neglect, 10, 54-65. https://ci.nii.ac.jp/naid/40016067078

[31] Howard, K.S. and Brooks-Gunn, J. (2009) The Role of Home-Visiting Programs in Preventing Child Abuse and Neglect. The Future of Children, 19, 119-146.

https://muse.jhu.edu/article/361496

https://doi.org/10.1353/foc.0.0032

[32] Ministry of Health, Labor and Welfare (2008) Verification Results Such as Deaths from Child Abuse. Committee on Verification of Requiring Protections Cases Such as Child Abuse by the Children's Section, Social Security Council, 4th Report. http://www.mhlw.go.jp/bunya/kodomo/dv20/dl/02.pdf

[33] Partners in Prevention: Official Members of the Child Abuse Prevention Network: Can We Prevent Child Abuse and Neglect? http://child-abuse.com

[34] Crouch, J.L., Skowronski, J.J., Milner, J.S., Harris, B. and DeKalb, I.L. (2008) Parental Responses to Infant Crying: The Influence of Child Physical Abuse Risk and Hostile Priming. Child Abuse \& Neglect, 32, 702-710.

https://www.researchgate.net/publication/5245448 https://doi.org/10.1016/j.chiabu.2007.11.002

[35] Yoshida, H., Hoashi, A. and Hoashi, E. (2002) The Significance of "Hugging" in Infancy. Early Childhood Education Association of Japan Annual Convention, (55), 330-331. https://ci.nii.ac.jp/naid/110002953828 
[36] Yamada, F., Tanaka, S., Hikone, M., Kudo, K., Hayashi, S. and Sadanaga, T. (2008) A Tentative Program for the Prevention of Shaken Baby Syndrome (SBS). Japanese Journal of Child Abuse and Neglect, 10, 118-123. https://ci.nii.ac.jp/naid/40016067085

[37] Zukawa, N. (2008) Father's Awareness of Child-Rearing and Child-Abuse Prevention in Infancy. The Journal of Child Health, 67, 403-410. https://ci.nii.ac.jp/naid/10024309396

[38] Ministry of Health, Labor and Welfare (2019) Verification Results Such as Deaths from Child Abuse. Committee on Verification of Requiring Protections Cases Such as Child Abuse by the Children's Section, Social Security Council, 15th Report. https://www.mhlw.go.jp/content/11900000/000533867.pdf

[39] Shimada, M. (2005) Trends in Maternal and Child Health Measures in Response to Mental Problems Related to Pregnancy and Childbirth. Current Information of Maternal \& Child Health, 51, 75-79. https://ci.nii.ac.jp/naid/40006797108

[40] Möhler, E., Matheis, V., Marysko, M., Finke, P., Kaufmann, C., Cierpka, M., Reck, C. and Resch, F. (2008) Complications during Pregnancy, Peri- and Postnatal Period in a Sample of Women with a History of Child Abuse. Journal of Psychosomatic Obstetrics \& Gynecology, 29, 193-198. https://www.ncbi.nlm.nih.gov/pubmed/18608822 https://doi.org/10.1080/01674820801934252

[41] Kaufman, J. and Zigler, E. (1989) The Intergenerational Transmission of Child Abuse. In: Cicchetti, D. and Carlson, V., Eds., Child Maltreatment, Cambridge University Press, Cambridge, 129-150.

https://psycnet.apa.org/record/1989-98324-005 https://doi.org/10.1017/CBO9780511665707.006

[42] Syoji, J. (2008) Infant Medical Examination as a Countermeasure for Abuse (2) from the Point of View of Clinical Psychology (Special Issue Maternal and Infant Medical Examination)-(Infant Medical Examination). Current Information of Maternal \& Child Health, 58, 97-100. https://ci.nii.ac.jp/naid/40016381258/en/?range $=0 \&$ sortorder $=0 \&$ start $=0 \&$ count $=0$

[43] Bowlby, J. (1973) Attachment and Loss. Vol. 2. Separation. Basic, New York. https://abebe.zohosites.com/files/John-Bowlby-Separation-Anxiety-And-Anger-Att achment-and-Loss-Vol-2-1976.pdf

[44] Konno, Y., Mizutani, T. and Hoshino, T. (2001) Consideration of the Early Findings and Early Educational Approach to Child Abuse-Establishing Mother-Child Attachment and Prevention of Intergenerational Transmission of Child Abuse. Annual Report of the Faculty of Education, Bunkyo University, 35, 105-117.

https://ci.nii.ac.jp/naid/110000330555/en/?range $=0 \&$ sortorder $=0 \&$ start $=0 \&$ count $=0$ 


\section{Appendices}

\section{Questionnaire}

An Exploration of the Relationship between Maternal and Child Factors Contributing to Child Abuse

The following questionnaire asks about your first child or about your relationship with that child.

1) Please tell us your age. Please enter $\bigcirc$ in the corresponding item.

( ) $15-19,(\quad$ ) $20-24,($ ) $25-29,(\quad$ ) $30-34,(\quad$ ) $35-39,(\quad$ ) $40-44,($ ) $45-49$

2) How old is your first child? Please enter $\bigcirc$ in the corresponding item.

( ) 0-year-old, ( ) 1 year old, ( ) 2 years old, ( ) 3 years old, ( ) 4 years old, ( ) 5 years old, ( ) 6 years old and older

3) When did you have a hard time physically and mentally after childbirth? Please enter $\bigcirc$ at the following times. You can select more than one.

( ) Less than one month, ( ) 1 month, ( ) 2 month, ( ) 3 month, ( ) 4 month, ( ) 5 month

( ) 6 month, ( ) 7 month, ( ) 8 month, ( ) 9 month, ( ) 10 month, ( ) 11 month

( ) 1 year old, ( ) 2 year old, ( ) 3 year old, ( ) 4 year old, ( ) 5 year old, ( ) 6 year old

4) What was the reason why you were physically and mentally difficult after childbirth? Please enter $\bigcirc$ at the following times. You can select any number of them.

( ) There was no person to consult.

( ) I couldn't balance housework and childcare.

( ) No one helped with childcare.

( ) The child didn't stop crying.

( ) I struggled with sleep deprivation.

( ) I didn't know a childcare method.

( ) I couldn't produce breastmilk.

( ) I didn't feel well.

( ) My husband did not understand.

( ) I abused my child.

( ) My child was a handful.

( ) My husband did not help me with childcare.

( ) I didn't have time for myself.

( ) I had to work for financial reasons.

( ) I could not get the understanding from my family other than my husband.

( ) Other

5) Have either you or your husband (person with whom you have an intimate relationship) performed the following actions towards your first child?

Please enter $\bigcirc$ for actions you took towards your child and $(?$ for actions taken by your husband (person with whom you have an intimate relationship).

( ) Hitting, ( ) Kicking, ( ) Pinching, ( ) Punching, ( ) Shaking violently

( ) Swinging around, ( ) Biting, ( ) Squeezing, ( ) Soaking in water, ( ) Burning with fire

( ) Strangle, ( ) Do not give food or milk, ( ) Do not change clothes

( ) Do not let him/her go to school, ( ) Leave him/her at a dangerous place

( ) He/she is sick but do not take him/her to the hospital., ( ) Lock up at home 


\section{Continued}

( ) Overlook violence against children from husbands, families, mistresses

( ) Ignoring, ( ) Loud scolding, ( ) Scaring, ( )Swear

( ) Familiar with terrible words, ( ) Forcing, ( ) Forcibly dragged, ( ) Leave infants in the car

( ) Sometimes an infant is left alone so you could go shopping.

( ) Leave him/her alone and go to work

( ) There is repeated domestic violence from the husband in the presence of children.

( ) Sexual assault on children

6) Do you know that the above actions are acts of abuse? Please enter $\bigcirc$ in any of the following items.

( ) I know, ( ) I did not know

7) I would like to ask about your first child. Please enter $\bigcirc$ in Yes or No.

a) My child has a delay in child development/physical growth.

Yes, No

b) My child is a premature baby.

Yes, No

c) My child is a twin, triplet, etc.

Yes, No

( children)

d) There was a time when parents and children are separated.

Yes, No

Ask the person who answered yes.

At that time, how old was your child? ( )

How long was the parent away? (

e) My child has a disability.

Yes, No

Ask the person who answered Yes. What kind of disability? (Content:

Yes, No

f) My child is aggressive to other children or siblings.

Yes, No

g) My child has a chronic illness (long-term illness).

Yes, No

h) My child often lies down.

Yes, No

i) My child has a regression to infantile behavior.

Yes, No

j) My child overeats.

Yes, No

k) My child has gaps in developmental expectations.

Yes, No

1) My child's height or weight doesn't follow the development curve of the mother-child handbook.

Yes, No

m) My child has hyperactivity (restlessness).

Yes, No

n) My child is rough and violent to his/her friends.

Yes, No

o) My child is cling on everyone.

Yes, No

p) My child is attached to my husband or the man I'm dating.

Yes, No

q) My child is crying terribly at night.

Yes, No

r) My child gets in trouble in kindergarten or preschool.

Yes, No

s) My child bullies his/her younger brothers or sisters.

Yes, No

t) My child is having trouble going to a cram school or lesson that I want him/her to attend.

Yes, No

u) My child sometimes eats alone while watching TV.

Yes, No 


\section{Continued}

8) Do you have any worries or thoughts regarding the following points in raising your first child now or in the past? Please enter $\bigcirc$ in Yes or No.

a) I am easily irritated by my child when I don't like my child's behavior.

Yes, No

b) May be worried that the child's development is delayed.

Yes, No

c) I feel I am being blamed for my child's behavior.

Yes, No

d) Compared to others, I feel like my child is the only child not raised properly.

Yes, No

e) I don't think I can raise my child well.

Yes, No

f) I am thinking other households have been able to raise children well.

Yes, No

g) I sometimes don't feel any affection for my child.

Yes, No

h) I think my child doesn't show affection towards me.

Yes, No

i) I think my child is discriminated against.

Yes, No

Ask the person who answered yes. Who do you think is discriminating? (

Yes, No

j) I sometimes wish that my child would disappear.

Yes, No

1) My first child was an unwanted pregnancy.

Yes, No

m) I have friends whom I can speak and ask to take care of my children.

Yes, No

n) I have arguments with my husband.

Yes, No

o) I have friendly conversations with my husband.

Yes, No

p) I have troubles with my neighbor.

Yes, No

q) I am worried about my own growing up and my relationship with my parents.

Yes, No

r) I remember that I was also abused.

Yes, No

s) I think I wasn't loved by my parents.

Yes, No

t) I currently or ever consume alcohol.

Yes, No

u) I may be frustrated by pregnancy or childbirth.

Yes, No

v) I have financial anxiety.

Yes, No

w) I don't want to do housework.

Yes, No

x) I want to do housework (laundry, cleaning, etc.) but I don't have time to do it.

Yes, No

9) Did you receive the following health guidance at this hospital? Please describe the level of satisfaction with the items you received. Please enter $\bigcirc$ in the corresponding item.
a) Pregnant midwife outpatient
b) Pre-mama class (parents' class)
c) First lactation guidance
d) Discharge guidance
e) Bathing instruction

Good, ok, not good

Good, ok, not good

Good, ok, not good

Good, ok, not good

Good, ok, not good

f) Breast milk outpatient

Good, ok, not good

g) One-month postpartum medical examination

Good, ok, not good

h) Medical examination for infant after 3 months

Good, ok, not good 


\section{Continued}

10) Did the above instructions help reduce your current stress? Please enter $\bigcirc$ for the degree of satisfaction in Yes or No.
a) Pregnant midwife outpatient
Yes, No
b) Pre-mama class (parents' class)
Yes, No
c) First lactation guidance
Yes, No
d) Discharge guidance
Yes, No
e) Bathing instruction
Yes, No
f) Breast milk outpatient
Yes, No
g) One-month postpartum medical examination
Yes, No
h) Medical examination for infant after 3 months
Yes, No

11) Please tell us about your future requests for health guidance from our hospital through this questionnaire. Please enter $\bigcirc$ in Yes or No.
a) I want you to increase the time for each individual instruction.
Yes, No
b) I would like to have home-visit nursing for childcare.
Yes, No
c) I would like you to consult with us regarding abuse.
Yes, No
d) I would like to have a consultation desk on the website.
Yes, No
e) I would like you to set up a consultation counter for outpatients.
Yes, No
f) Other
Yes, No 